\title{
Terminologia do Turismo: inovação lexical e codificação lexicográfica no campo das atividades de aventura
}

\author{
Ivanir Azevedo Delvizio* \\ Sheila de Carvalho Pereira Gonçalves **
}

\begin{abstract}
RESUMO: $\mathrm{O}$ objetivo deste trabalho é apresentar uma análise das unidades terminológicas que designam as atividades relacionadas ao turismo de aventura, observando novos termos usados nesse domínio e seu registro em obras lexicográficas e terminográficas. O levantamento dos termos foi realizado com base em um corpus composto por cerca de 50 textos sobre Turismo de Aventura, englobando documentos da Associação Brasileira de Normas Técnicas (ABNT), manuais do Ministério do Turismo e da Associação Brasileira de Empresas de Ecoturismo e Turismo de Aventura (ABETA) e textos acadêmicos. O programa de análise lexical usado para armazenamento e processamento dos textos foi o WordSmith Tools. Para verificação da codificação, foram

ABSTRACT: The aim of this work is to present an analysis of terminological units that designate activities related to adventure tourism, observing new terms used in this area and their registration in specialized and general language dictionaries. The selection of terms was based on a corpus consisted of about 50 texts related to Adventure Tourism, comprising Standards Brazilian Association (ABNT) documents, guidelines of Brazilian Tourism Department and Brazilian Association of Adventure Tourism and Ecotourism Companies (ABETA) and academic works. The lexical analysis software WordSmith Tools was used to store and process texts. In order to check the registration, three general language dictionaries and six dictionaries specialized in Tourism were used.
\end{abstract} utilizados três dicionários de língua geral e seis dicionários da área de turismo.

PALAVRAS-CHAVE: Léxico; Turismo; Atividades de Aventura.

KEYWORDS: Lexicon. Tourism. Adventure Activities.

\section{Delimitação do domínio e objeto de estudo}

Segundo a definição da Organização Mundial do Turismo (2001, p. 38), o turismo compreende "as atividades que as pessoas realizam durante viagens e estadas em lugares diferentes do seu entorno habitual, por um período inferior a um ano, com finalidade de lazer, negócios ou outras". Essas atividades mobilizam, de forma coordenada e complexa, diferentes setores da economia, tais como: transportes, agências de viagens, meios de hospedagem, serviços de alimentação, eventos, instalações para atividades diversas, lazer e entretenimento e

\footnotetext{
* Doutora em Análise Linguística, Câmpus de Rosana, Universidade Estadual Paulista - UNESP.

** Doutora em Análise Linguística, Unidade Acadêmica Especial de Letras e Linguística, Universidade Federal de Goiás - Catalão.
} 
outros serviços receptivos (IGNARRA, 2003). Um estudo amplo sobre o léxico do Turismo, portanto, envolveria todos esses setores, podendo cada um deles constituir um campo nocional a ser explorado. Como consequência dessa complexidade de subcampos contemplados pelo Turismo, tem-se, nesse domínio, um léxico extremamente rico (ARAGÓN COBO; EURRUTIA CAVERO; PLANELLES IBÁNEZ, 2007, p. 235).

Além de envolver diversos setores, também há que se destacar o processo de especialização pelo qual o Turismo vem passando. Como forma de organizá-lo para fins de planejamento e gestão, foram sendo estabelecidos os segmentos turísticos. Embora existam outros, o Ministério do Turismo (BRASIL, 2006) destaca alguns principais: turismo cultural, turismo rural, turismo náutico, turismo de negócios e eventos, turismo de estudos e intercâmbio, turismo de saúde, turismo de sol e praia, turismo de pesca, turismo de esporte, ecoturismo e turismo de aventura.

Diante desse cenário amplo e heterogêneo, há pesquisas e obras que contemplam vários subcampos do turismo, em que são selecionados os termos fundamentais ou mais frequentes de cada um deles, e há aquelas que tratam especificamente de certos subcampos ou segmentos. Este trabalho, especificamente, teve como objeto de estudo os termos que designam as atividades esportivas e recreativas relacionadas ao turismo de aventura.

O turismo de aventura pode ser definido como:

[...] o segmento do mercado turístico que promove a prática de atividades de aventura e esporte recreacional, em ambientes naturais e espaços urbanos [...], que envolvam emoções e riscos controlados, exigindo o uso de técnicas e equipamentos específicos, a adoção de procedimentos para garantir a segurança pessoal e de terceiros e o respeito ao patrimônio ambiental e sócio-cultural. (BRASIL, 2005, p. 9 , grifo nosso).

Na definição anterior, podemos perceber, por meio das expressões em destaque, que o turismo de aventura estabelece pontos de contato importantes com as áreas ambiental e esportiva. Ao definir esse segmento, por conseguinte, é oportuno distingui-lo de alguns outros com os quais pode estar relacionado, a saber: turismo de esportes, ecoturismo, turismo de sol e praia e turismo rural.

Em relação ao turismo de esportes, a diferença repousa no fato de que as atividades esportivas praticadas no âmbito do turismo de aventura são de caráter recreativo e não competitivo, ao passo que o turismo de esportes envolve atividades esportivas de competição, institucionalizadas e regulamentadas, podendo compreender tanto a prática quanto a observação. 
No que concerne à sua interface com o ecoturismo, Buckley e Uvinha (2011, p. 3) explicam que o Turismo de Aventura "está intimamente relacionado com o turismo na natureza, confundindo-se com ele em algumas ocasiões. Contudo, os produtos de turismo na natureza enfocam a observação, enquanto os de turismo de aventura, a ação". Para complementar, também podemos dizer que o ecoturismo é sempre desenvolvido em contato com a natureza, buscando incentivar sua conservação e promover ações de educação ambiental. Já o turismo de aventura pode ser realizado tanto em áreas urbanas quanto em áreas naturais, como praias e zonas rurais, também podendo estar interligado aos segmentos denominados turismo de sol e praia e turismo rural.

Em relação a este último, vale observar que, enquanto no Turismo de Aventura o turista tem como objetivo a realização das atividades, no Turismo Rural, ele é motivado pela fuga do meio urbano em busca de tradição, cultura e do modo de viver do campo (BRASIL, 2010b, p. $65)$.

Essas distinções, no entanto, são apenas conceituais, pois, na prática, os segmentos podem estar conjugados, e as atividades esportivas e recreativas podem ser exploradas por segmentos diversos de acordo com o enfoque que se deseja dar.

Segundo Estornell Pons (2013, p. 36), o acervo lexical que compreende tais atividades "é constituído e ampliado à medida que vão surgindo diferentes atividades físico-esportivas e de lazer que vão sendo incorporadas ao setor de turismo". Conforme sua observação, uma parte desse acervo "são palavras que estão assentadas na língua comum e codificadas lexicograficamente, já que nomeiam esportes e atividades físicas praticadas [...] há muito tempo" (ESTORNELL PONS, 2013, p. 36). Outra parte desse acervo refere-se a palavras que nomeiam atividades de criação recente. Além disso, conforme complementam Betrán e Betrán (1995, p. 109), além de novas práticas, surgem constantemente variantes das atividades já existentes e, por conseguinte, novos termos para nomeá-las. Dessa forma, “o vocabulário desse âmbito se encontra em constante mudança e crescimento em consonância com a ampliação do repertório de atividades oferecidas no setor do turismo" (ESTORNELL PONS, 2013, p. 53).

Neste artigo, pretende-se analisar os termos que designam as atividades esportivas e recreativas desenvolvidas no turismo de aventura no que se refere à inovação lexical nesse domínio, tendo como um dos parâmetros norteadores a verificação de seu registro em dicionários de língua geral e especializados, buscando oferecer um panorama geral desse conjunto terminológico. Para isso, o artigo foi organizado nas seguintes partes: considerações 
acerca do alcance designativo do termo atividades de aventura; apresentação das propostas de classificação das atividades de aventura; metodologia de seleção do conjunto lexical a ser analisado; resultados da verificação do registro das unidades selecionadas em obras lexicográficas e terminográficas, análise dos dados e considerações finais ${ }^{1}$.

\section{Atividades de aventura: alcance designativo}

O turismo de aventura é um segmento recente e, como tal, ainda apresenta algumas questões conceituais indefinidas. Figueiredo (2012, p. 65) faz uma revisão sobre âs diferentes terminologias adotadas nos estudos sobre as atividades de aventura, analisando artigos de diferentes autores: "de acordo com a análise desses artigos, nota-se uma diversidade de termos nos quais os autores se pautam para se referenciarem às atividades de aventura [...], não havendo uma conceituação consolidada".

As atividades inseridas no conjunto lexical estudado em nossa pesquisa, portanto, podem receber diferentes denominações de estudiosos de diversas áreas, tais como: atividades na natureza, atividade fisicas na natureza, atividade fisicas de aventura na natureza (AFAN), esportes radicais, esportes de aventura e atividades de aventura (BETRÁN; BETRÁN, 1995; MOREIRA; SCHWARTZ, 2010; ROMARIZ; GUIMARÃES; MARINHO, 2011; UVINHA, 2001; MARINHO, 2004; CARDOSO; SILVA; FELIPE, 2006; TAHARA; CARNICELLI FILHO; SCHWARTZ, 2006; GOMES; ISAYAMA citados por FIGUEIREDO, 2012).

Conforme relata Figueiredo (2012, p. 65), “alguns estudos, até mesmo, buscam subsidiar a preferência por um termo específico, enquanto outros os utilizam como sinônimos". No que se refere às terminologias adotadas para as atividades de aventura, embora praticamente todos os estudos analisados pela autora tenham feito uso do termo atividades fisicas de aventura na natureza (AFAN), sugerido inicialmente por Betrán e Betrán (1995), há discussões na literatura que questionam sua utilização de modo generalizado.

Marinho (2004a, p. 4 apud FIGUEIREDO, 2012, p. 65-66), por exemplo, considera que o adjetivo fisicas soa como um pleonasmo quando associado às atividades, sugerindo, assim, a utilização do termo atividades na natureza. Entretanto, a terminologia que privilegia o uso da palavra natureza, como, por exemplo, atividades de aventura na natureza ou, simplesmente,

\footnotetext{
${ }^{1}$ Os dados analisados neste artigo foram obtidos de pesquisa financiada pela FAPESP, que tem como objetivo a elaboração de um glossário de turismo.
} 
atividades na natureza, por sua vez, deixa de abranger as atividades realizadas no meio urbano ou em locais com estruturas artificiais. Considerando-se que essas atividades não são, necessariamente, desenvolvidas apenas em ambientes naturais, esses termos são questionáveis.

A $\operatorname{ABNT}(2007$, p. 1), na NBR 15500, que trata da terminologia do turismo de aventura, traz o termo atividades de turismo de aventura, definindo-o como: "atividades oferecidas comercialmente, usualmente adaptadas das atividades de aventura, que tenham ao mesmo tempo o caráter recreativo e envolvam riscos avaliados, controlados e assumidos", dando ênfase à sua oferta como produto turístico por meio da inserção da palavra turismo para compor a designação.

O Ministério do Turismo (BRASIL, 2006, p. 40), por sua vez, define o termo atividades de aventura como sendo:

[...] as experiências físicas e sensoriais recreativas que envolvem desafio, riscos avaliados, controláveis e assumidos que podem proporcionar sensações diversas: liberdade; prazer; superação, etc. — a depender da expectativa e experiência de cada pessoa e do nível de dificuldade da cada atividade.

No caso dos termos atividades de turismo de aventura, atividades de aventura ou esportes de aventura, a expressão aventura (do latim adventura, o que há por vir) implica a ideia de desafio e risco, nem sempre presente em algumas atividades ou presente em graus variados. Já em relação ao termo esportes de aventura, voltaríamos à questão do fator competição vinculado à palavra esporte.

Questão terminológica semelhante é discutida no trabalho de Estornell Pons (2013), que trabalha com o espanhol europeu. A autora assinala a diferença entre as expressões turismo activo e turismo de aventura na Espanha. Segundo a autora:

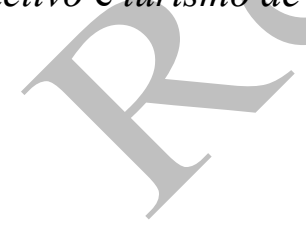

A denominação turismo activo possui um maior alcance designativo, principalmente nos textos de caráter promocional ou comercial, já que inclui atividades consideradas «de aventura»e algumas outras que não contêm esse traço, mas que são atividades esportivas, lúdicas ou de lazer e meio ambiente que não envolvem o perigo ou a emoção característicos das atividades de aventura propriamente ditas, e que, além disso, são praticadas em recintos e lugares a princípio não próprios ao turismo. Tal é o caso de atividades como golfe, arco e flecha, tiro ao prato, pesca, fotografia, observação de aves, observação astronômica, observação de fauna e flora, observação de baleias, passeios em muares, visitas a haras, visitas a criações de gado, oficinas de 
natureza, gincana, combat, laser, paintball ou pebolim. (ESTORNELL PONS, 2013, p. 35-36, tradução nossa) ${ }^{2}$

Segundo Estornell Pons (2013, p. 35), “a denominação turismo activo possui um maior alcance designativo", abrangendo, além das atividades de aventura, que pressupõem perigo e emoção, atividades esportivas, lúdicas e de lazer praticadas em diferentes ambientes. $\mathrm{Na}$ literatura brasileira, foram encontrados os termos turismo de atividade (SWARBROOKE; HORNER, 2002) e turismo ativo, sendo este último definido como "turismo alternativo ao tradicional, cuja maior motivação recai no exercício de algum tipo de interatividade com o entorno, seja físico ou de caráter lúdico" (LOHMANN; PANOSSO NETO, 2012, p. 176). Entretanto, esses termos parecem não ter um uso tão difundido no Brasil quanto turismo activo tem na Espanha.

Citamos, por último, o posicionamento adotado por Moreira (2010, p. 116; 600), que, ao organizar a árvore de domínio ${ }^{3}$ do turismo em português europeu, propõe um campo genérico intitulado actividades desportivas e recreativas ${ }^{4}$, no qual insere atividades de diferentes naturezas desenvolvidas no turismo. Essa proposta pareceu-nos a mais adequada pensando-se na futura organização de uma árvore do domínio do turismo. Sendo assim, denominaremos o campo em estudo de atividades esportivas e recreativas com o intuito de nele contemplar uma gama maior de atividades praticadas no âmbito do turismo, sejam elas realizadas em espaços naturais ou construídos, rurais ou urbanos, fechados ou ao ar livre; oferecidas para fins turísticos, esportivos ou recreativos e que possam envolver ação e ou observação.

\section{Classifịcação das atividades de aventura}

Com o intuito de compreendermos e organizarmos os termos do campo das atividades de aventura, alguns modelos de classificação foram examinados.

\footnotetext{
${ }^{2}$ Tiro ao prato ou tiro esportivo "é um esporte praticado individualmente ou por equipe que tem por objetivo atingir alvos que podem ser fixos, em movimento e ao voo, por projéteis disparados por armas de fogo e ar comprimido" (TUBINO; TUBINO; GARRIDO, 2007, p. 315).

${ }^{3}$ Segundo Krieger e Finatto (2004, p. 134), “uma árvore de domínio é um diagrama hierárquico composto por termos-chave de uma especialidade, semelhante a um organograma" e serve "como uma organização possível para uma especialidade ou uma ciência, de modo que o pesquisador possa, baseado nele, compreender algumas de suas hierarquias básicas e também situar um recorte do reconhecimento terminológico para seu dicionário".

${ }^{4}$ Com relação ao caso tratado, Moreira $(2010$, p. 116; 600) estabelece a seguinte hierarquia: Turismo > B. Oferta turística > B.1 Atracções turísticas > B.1.4 Actividades desportivas e recreativas.
} 
Dentre eles, destacamos a proposta de classificação taxonômica das atividades físicas de aventura na natureza de Betrán e Betrán (1995, 116-117), que parte de uma seleção de critérios englobados em diferentes dimensões: dimensão física (água, ar e terra; plano horizontal ou vertical; meio estável ou instável); dimensão pessoal (hedonismo/menos esforço ou ascetismo/mais esforço; sensação de prazer/relaxamento ou de risco/vertigem); recursos biotecnológicos (artefato motorizado, artefato mecânico/tecnológico, suporte animal ou o próprio corpo); dimensão ético-ambiental (alto, médio ou baixo impacto ecológico) e dimensão social (prática individual, coletiva com colaboração ou coletiva sem colaboração). Os autores também citam critérios como o grau de deslizamento e de competitividade. Nessa classificação, a atividade de cicloturismo, por exemplo, poderia ser classificada como: terrestre, horizontal, estável, hedonista, de prazer e relaxamento, com uso de artefato mecânico/tecnológico, de baixo impacto ecológico e de prática coletiva sem colaboração.

Funollet (1995, p. 127-129) também apresenta uma proposta de classificação dos esportes de aventura na natureza, ordenando-as em oito grupos: trajetória (bidimensional ou tridimensional); plano (vertical ou horizontal); elemento (estável: terra, rocha, neve e gelo ou instável: água e ar); contato (direto ou indireto); deslocamento (caminhando, rodando, deslizando, cavalgando, nadando, flutuando, escalando, fazendo rapel, mergulhando ou voando); energia (autogerada ou gerada - animal, ambiente, gravidade, hidráulica, eólica, solar ou motor); ação (individual, imbricada ou em equipe) e ecossistema (pelágico, fluvial, lacustre, rupestre, cavernícola, florestal, arbustivo, campestre, agrícola, deserto árido, deserto frio, alta montanha, urbanizado e outros).

Não obstante a existência dessas classificações mais complexas, observamos, principalmente, nos textos que compõem o nosso corpus, que as atividades de aventura costumam ser classificadas em três grupos, utilizando-se os elementos da natureza: água, ar e terra. A respeito desse tipo de classificação, cabe observar que, em alguns casos, a atividade pode envolver mais de um elemento, podendo ser denominada mista (que neste trabalho indicamos por meio de um asterisco). Alguns autores adotam essa última categoria para tais atividades, enquanto outros as inserem em uma das outras categorias (água, ar ou terra), de acordo com o elemento predominante ou algum outro critério que estabeleça. Uma atividade como o bungee jump, por exemplo, envolve os elementos ar e terra. Em casos como esse, costuma-se adotar como critério a existência ou não de um ponto de contato com a terra. $\mathrm{Na}$ atividade citada, o participante salta e se desloca verticalmente no ar, mas se mantém conectado 
a um ponto fixo no solo por meio de uma corda elástica. De acordo com esse critério, essa atividade seria classificada como terrestre.

Para os fins deste estudo, foi adotada inicialmente a classificação tripartite em água, ar e terra, também utilizada nas publicações do Ministério do Turismo, à qual foi acrescentado posteriormente o elemento neve. No caso de uma mesma atividade envolver ou poder envolver mais de um elemento, foram considerados os seguintes critérios: atividade terrestre, quando mantém um ponto de contato com a terra durante sua prática; atividade aquática, quando, não havendo ponto fixo terrestre, mantém um ponto de contato com a água; atividade aérea, quando não mantém ponto de contato com a terra e nem com a água. As atividades que combinavam duas ou mais atividades de elementos diferentes foram classificadas como combinadas. Além disso, também foi acrescentado, provisoriamente, um campo para as atividades de observação, por contemplarem tanto ambientes terrestres quanto aquáticos.

\section{Composição do corpus, seleção e sistematização dos termos}

Os termos que analisaremos foram extraídos de um Corpus de Turismo de Aventura em Português (CTAP) composto por cerca de 50 textos (782.447 tokens e 38.665 types $)^{5}$, em formato digital, que versam sobre o Turismo de Aventura, incluindo normas da Associação Brasileira de Normas Técnicas (ABNT), manuais e guias do Ministério do Turismo e da Associação Brasileira de Empresas de Ecoturismo e Turismo de Aventura (ABETA) e trabalhos acadêmicos. Também foram utilizados dicionários de língua geral e especializados na área de esportes e turismo. Vale destacar que dispomos de dois corpora comparáveis em Inglês e Espanhol especializados em Turismo de Aventura (CTAI e CTAE), aos quais recorremos durante a análise. As obras que compõem o CTAP foram convertidas para o formato somente texto (.txt) e armazenadas no programa de análise lexical WordSmith Tools. Essa ferramenta "fornece, a partir de textos pré-selecionados, concordâncias para a palavra de busca, clusters (agrupamentos frequentes), listas das palavras mais frequentes num texto, bem como palavraschave de um texto" (TAGNIN, 2002, p. 204). Com a ferramenta Wordlist, criamos uma lista das palavras contidas nos textos. O software também permite a criação de linhas de concordância (Concordance), que oferece a visualização de todas as linhas nas quais um determinado termo ocorre, permitindo a visualização dos cotextos e identificação de termos complexos ou

\footnotetext{
5 Tokens refere-se ao "número de itens (ou ocorrências)", e types, ao "número de formas (ou vocábulos)" (BERBER SARDINHA, 1999, p. 6).
} 
sintagmáticos, ou seja, "unidades terminológicas constituídas de diversos lexemas" (BARROS, 2004, p. 101).

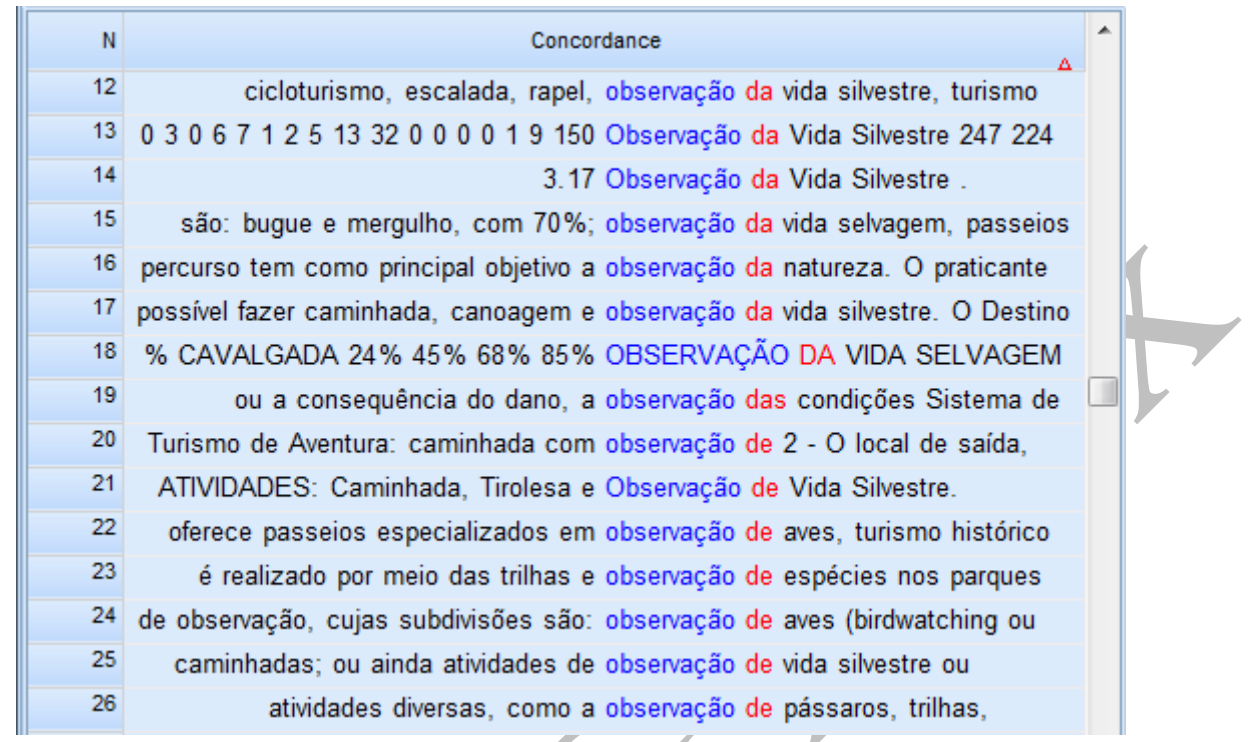

Figura 1. Linhas de concordância com a palavra observação.

Ao se clicar em uma linha de concordância, pode-se visualizar o contexto em que o termo ocorre. Com base em uma análise global da lista de palavras, linhas de concordância e contextos, os termos que designam atividades esportivas e recreativas foram selecionados e, posteriormente, organizados em um sistema conceptual. Vale destacar que os termos polissêmicos foram inseridos no sistema com uma indicação numérica diferente (1 e 2) para cada acepção.

\section{1. atividades esportivas e recreativas}

\section{1 atividades na água}

1.1.1 boia-cross, acqua-ride, acqua ride

1.1.2 body-board, bodyboard, bodyboarding

1.1.3 bodysurfe, bodysurf

1.1.4 canoagem

1.1.4.1 caiaque oceânico, canoagem oceânica, seakayak

1.1.4.2 caiaque surfe, surf kayak

1.1.4.3 caiaque turístico, kayaktouring

1.1.4.4 duck, caiaque inflável

1.1.4.5 rafting

1.1.4.5.1 rafting em águas brancas

1.1.5 esqui aquático, esqui ${ }^{1}$

1.1.6 hidrospeed

1.1.7 jet ski, jet-ski

1.1.8 kitesurfe

1.1.9 mergulho

1.1.9.1 mergulho autônomo, mergulho autônomo recreativo, mergulho recreativo, 
mergulho autônomo turístico

1.1.9.2 mergulho em caverna

1.1.9.3 mergulho livre

1.1.9.4 mergulho noturno

1.1.10 remo

1.1.11 snorkeling, flutuação

1.1.12 stand up [paddle], [SUP]

1.1.13 surfe, surf

1.1 .14 vela

1.1.15 wakeboard

1.1.16 windsurfe, prancha a vela

1.2 atividades no ar

1.2.1 balonismo

1.2.2 base jump

1.2.3 paraquedismo

1.2.4 salto duplo

1.2.5 skydive

1.2.6 skysurfe, sky surf, skysurfing

1.2.7 ultraleve

1.2.8 voo livre ${ }^{1}$

1.2.8.1 asa-delta, asa delta, voo livre ${ }^{2}$

1.2.8.2 parapente, paraglider, paragliding

\section{3 atividades na terra}

1.3.1 arco e flecha, arco-e-flecha

1.3.2 arvorismo*, arborismo

1.3.3 bungee jump*, bunguee jumping, high jump

1.3.4 cachoeirismo*, cascading

1.3.5 caminhada $^{1}$

1.3.5.1 caminhada ${ }^{2}$, hiking

1.3.5.2. trekking, caminhada de longo curso, travessia

1.3.6 canionismo*, canyoning

1.3.7 ciclismo

1.3.8 cicloturismo

1.3.9 corrida de orientação, orientação

1.3.10 escalada

1.3.10.1 big wall, escalada em big wall

1.3.10.2 boulder, escalada de bloco, bouldering, escalada em bloco

1.3.10. 3 escalada artificial

1.3.10. 4 escalada em rocha

1.3.10. 5 escalada esportiva

1.3.10. 6 muro artificial

1.3.11 espeleoturismo*, caving, cavernismo

1.3.11.1 espeleoturismo vertical

1.3.12 le parkour, [PK]

1.3.13 montanhismo, alpinismo ${ }^{1}$

1.3.12.1 alpinismo $^{2}$

1.3.14 mountain bike, mountain biking

1.3.15 paintball

1.3.16 quadriciclo

1.3.17 rapel, rappel

1.3.18 sandboard, surfe de areia

1.3.19 skate, skateboarding, skateboard, esqueite

1.3.20 tirolesa*

1.3.21 turismo equestre, cavalgada

1.3.22 turismo fora de estrada, turismo fora-de-estrada, fora de estrada, off-road

1.3.23 via ferrata

1.4 atividades na neve

1.4.1 esqui ${ }^{2}$ 
1.4.2 snowboard

1.5 atividades combinadas

1.5.1 corrida de aventura

1.6 atividades de observação

1.6.1 observação da vida silvestre, observação de vida silvestre, observação da vida selvagem, observação de fauna e flora.

1.6.2 observação de aves; observação de pássaros

1.6.3 observação de baleias

\section{Codificação lexicográfica e terminográfica}

Para verificar a codificação lexicográfica das unidades selecionadas, consultamos três obras de língua geral e seis obras relacionadas à área do turismo, mencionadas abaixo. Essa verificação é apresentada logo adiante.

1. ACADEMIA BRASILEIRA DE LETRAS. Vocabulário ortográfico da língua portuguesa. 5. ed. São Paulo: Global, 2009.

2. FERREIRA, Aurélio Buarque de Holanda. Novo dicionário Aurélio da língua portuguesa. 3. ed. Curitiba: Positivo, 2004.

3. HOUAISS, Antônio. Dicionário Houaiss eletrônico da língua portuguesa. Rio de Janeiro: Objetiva, 2009.

4. FERREIRA, Fernando Luiz Vieira. Dicionário Brasileiro de Turismo. Rio de Janeiro: Colorama, 1975.

5. PELLEGRINI FILHO, Américo. Dicionário Enciclopédico de Ecologia e Turismo. São Paulo: Manole, 2000.

6. FERRI, Cássia; RUSCHMANN, Dóris Van de Meene. Turismo: Visão e Ação (Glossário), ano 2, n. 4, p. 9-30, fev. 2000.

7. VIEIRA, Elenara Vieira de; CÂNDIDO, Indio. Glossário Técnico Gastronômico, hoteleiro e turístico. 2.ed. Caxias do Sul: Educs, 2003.

8. BRAGA, Robério. Dicionário de Turismo. São Paulo: Uniletras, 2003.

9. GARCIA, Maura Xavier. Vocabulário para turismo: português-inglês. São Paulo: SBS, 2004.

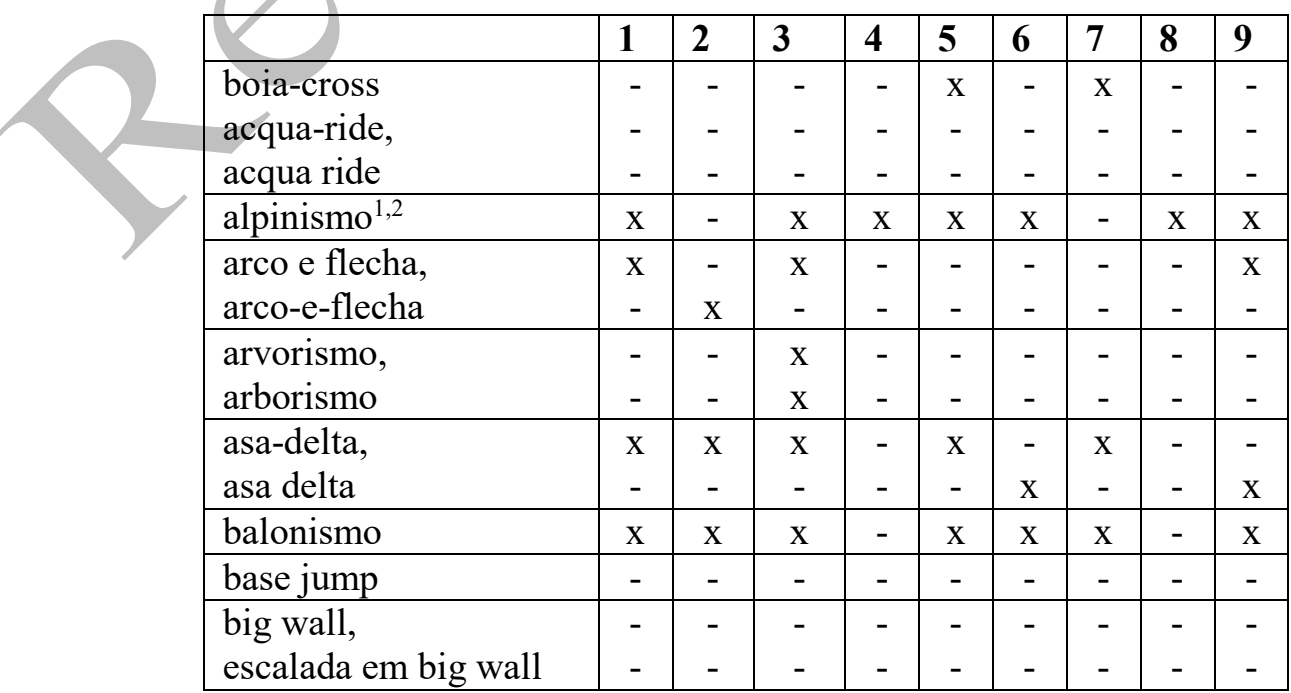




\begin{tabular}{|c|c|c|c|c|c|c|c|c|c|}
\hline $\begin{array}{l}\text { body-board, } \\
\text { bodyboard, } \\
\text { bodyboarding }\end{array}$ & $\begin{array}{l}- \\
- \\
-\end{array}$ & $\begin{array}{l}- \\
- \\
-\end{array}$ & $\begin{array}{l}\mathrm{x} \\
- \\
\mathrm{x}\end{array}$ & $\begin{array}{l}- \\
- \\
-\end{array}$ & $\begin{array}{l}- \\
- \\
-\end{array}$ & $\begin{array}{l}- \\
- \\
-\end{array}$ & $\begin{array}{l}- \\
- \\
-\end{array}$ & $\begin{array}{l}- \\
- \\
-\end{array}$ & $\begin{array}{l}- \\
- \\
-\end{array}$ \\
\hline $\begin{array}{l}\text { bodysurfe, } \\
\text { bodysurf }\end{array}$ & $\begin{array}{l}- \\
-\end{array}$ & $\begin{array}{l}- \\
-\end{array}$ & $\begin{array}{l}- \\
-\end{array}$ & $\begin{array}{l}- \\
-\end{array}$ & $\begin{array}{l}- \\
-\end{array}$ & $\begin{array}{l}- \\
-\end{array}$ & $\begin{array}{l}- \\
-\end{array}$ & $\begin{array}{l}- \\
-\end{array}$ & $\begin{array}{l}- \\
-\end{array}$ \\
\hline $\begin{array}{l}\text { boulder, } \\
\text { escalada de bloco, } \\
\text { bouldering, } \\
\text { escalada em bloco }\end{array}$ & $\begin{array}{l}- \\
- \\
- \\
-\end{array}$ & $\begin{array}{l}- \\
- \\
- \\
-\end{array}$ & $\begin{array}{l}- \\
- \\
- \\
-\end{array}$ & $\begin{array}{l}- \\
- \\
- \\
-\end{array}$ & $\begin{array}{l}- \\
- \\
- \\
-\end{array}$ & $\begin{array}{l}- \\
- \\
- \\
-\end{array}$ & $\begin{array}{l}- \\
- \\
- \\
-\end{array}$ & $\begin{array}{l}- \\
- \\
- \\
-\end{array}$ & $\begin{array}{l}- \\
- \\
- \\
-\end{array}$ \\
\hline $\begin{array}{l}\text { bunguee jump, } \\
\text { bunguee jumping, } \\
\text { high jump }\end{array}$ & $\begin{array}{l}- \\
- \\
-\end{array}$ & $\begin{array}{l}- \\
- \\
-\end{array}$ & $\begin{array}{l}\mathrm{X}- \\
-\end{array}$ & $\begin{array}{l}- \\
- \\
-\end{array}$ & $\begin{array}{l}\mathrm{x} \\
\mathrm{x} \\
\mathrm{x}\end{array}$ & $\begin{array}{l}- \\
- \\
-\end{array}$ & $\begin{array}{l}\mathrm{x} \\
- \\
\mathrm{x}\end{array}$ & $\begin{array}{l}- \\
- \\
-\end{array}$ & $\begin{array}{l}- \\
- \\
-\end{array}$ \\
\hline $\begin{array}{l}\text { cachoeirismo, } \\
\text { cascading }\end{array}$ & $\begin{array}{l}- \\
- \\
\end{array}$ & $\begin{array}{l}- \\
-\end{array}$ & $\begin{array}{l}- \\
-\end{array}$ & $\begin{array}{l}- \\
-\end{array}$ & $\begin{array}{l}- \\
-\end{array}$ & $\begin{array}{l}- \\
-\end{array}$ & $\begin{array}{l}- \\
-\end{array}$ & $\begin{array}{l}- \\
-\end{array}$ & - \\
\hline $\begin{array}{l}\text { caiaque surfe, } \\
\text { surf kayak }\end{array}$ & $\begin{array}{l}- \\
-\end{array}$ & $\begin{array}{l}- \\
-\end{array}$ & $\begin{array}{l}- \\
-\end{array}$ & $\begin{array}{l}- \\
-\end{array}$ & $\begin{array}{l}- \\
-\end{array}$ & - & - & $\begin{array}{l}- \\
-\end{array}$ & - \\
\hline $\begin{array}{l}\text { caiaque turístico, } \\
\text { kayaktouring }\end{array}$ & $\begin{array}{l}- \\
- \\
\end{array}$ & $\begin{array}{l}- \\
-\end{array}$ & $\begin{array}{l}- \\
-\end{array}$ & $\begin{array}{l}- \\
-\end{array}$ & - & - & - & $\begin{array}{l}- \\
-\end{array}$ & - \\
\hline caminhada $^{1,2}$ & $\mathrm{x}$ & $\mathrm{x}$ & $\mathrm{x}$ & - & $x$ & - & $\mathrm{x}$ & - & $\mathrm{x}$ \\
\hline $\begin{array}{l}\text { canionismo, } \\
\text { canyoning }\end{array}$ & $\begin{array}{l}- \\
-\end{array}$ & $\begin{array}{l}- \\
-\end{array}$ & - & - & $\overline{-}$ & $\mathrm{x}$ & - & $\begin{array}{l}- \\
-\end{array}$ & $\begin{array}{l}- \\
-\end{array}$ \\
\hline canoagem & $\mathrm{x}$ & $\mathrm{x}$ & $x$ & - & $\mathrm{x}$ & - & $\mathrm{x}$ & - & - \\
\hline $\begin{array}{l}\text { caiaque oceânico, } \\
\text { canoagem oceânica, } \\
\text { seakayak }\end{array}$ & $\begin{array}{l}- \\
- \\
-\end{array}$ & $\begin{array}{l}- \\
- \\
-\end{array}$ & - & $\begin{array}{l}- \\
- \\
-\end{array}$ & - & $\begin{array}{l}- \\
- \\
-\end{array}$ & $\begin{array}{l}- \\
- \\
-\end{array}$ & $\begin{array}{l}- \\
- \\
-\end{array}$ & $\begin{array}{l}- \\
- \\
-\end{array}$ \\
\hline ciclismo & $\mathrm{x}$ & $\mathrm{x}$ & $\mathrm{x}$ & - & $\mathrm{x}$ & - & - & - & - \\
\hline cicloturismo & -1 & - & - & - & - & $\mathrm{x}$ & - & - & - \\
\hline corrida de aventura & - & - & - & - & - & - & - & - & - \\
\hline $\begin{array}{l}\text { corrida de orientação, } \\
\text { orientação }\end{array}$ & - & - & $\begin{array}{l}- \\
-\end{array}$ & $\begin{array}{l}- \\
-\end{array}$ & $\begin{array}{l}- \\
-\end{array}$ & - & - & - & $\begin{array}{l}- \\
-\end{array}$ \\
\hline $\begin{array}{l}\text { duck, } \\
\text { caiaque inflável }\end{array}$ & - & $\begin{array}{l}- \\
-\end{array}$ & $\begin{array}{l}- \\
-\end{array}$ & $\begin{array}{l}- \\
-\end{array}$ & - & - & - & - & - \\
\hline escalada & $\mathrm{x}$ & - & $\mathrm{x}$ & $\mathrm{x}$ & - & $\mathrm{x}$ & - & $\mathrm{x}$ & - \\
\hline escalada artificial & - & - & - & - & - & - & - & - & - \\
\hline escalada em rocha & - & - & - & - & - & - & - & - & - \\
\hline escalada esportiva & - & - & - & - & - & - & - & - & - \\
\hline $\begin{array}{l}\text { espeleoturismo, } \\
\text { caving, } \\
\text { cavernismo }\end{array}$ & $\begin{array}{l}- \\
- \\
-\end{array}$ & $\begin{array}{l}- \\
- \\
-\end{array}$ & $\begin{array}{l}- \\
- \\
-\end{array}$ & $\begin{array}{l}- \\
- \\
-\end{array}$ & $\begin{array}{l}- \\
- \\
-\end{array}$ & $\begin{array}{l}- \\
- \\
-\end{array}$ & $\begin{array}{l}- \\
- \\
-\end{array}$ & $\begin{array}{l}- \\
- \\
-\end{array}$ & $\begin{array}{l}- \\
- \\
-\end{array}$ \\
\hline espeleoturismo vertical & - & - & - & - & - & - & - & - & - \\
\hline esqui ${ }^{1,2}$ & $\mathrm{x}$ & - & $\mathrm{x}$ & - & - & - & - & - & - \\
\hline esqui aquático & - & $\mathrm{x}$ & $\mathrm{x}$ & $\mathrm{x}$ & - & - & - & $\mathrm{x}$ & $\mathrm{x}$ \\
\hline hidrospeed & - & - & - & - & - & - & - & - & - \\
\hline hiking & - & - & - & - & $\mathrm{x}$ & $\mathrm{x}$ & $\mathrm{x}$ & - & $\mathrm{x}$ \\
\hline $\begin{array}{l}\text { jet ski, } \\
\text { jet-ski }\end{array}$ & $\begin{array}{l}- \\
-\end{array}$ & $\begin{array}{l}- \\
\mathrm{x}\end{array}$ & $\begin{array}{l}x \\
-\end{array}$ & $\begin{array}{l}- \\
-\end{array}$ & - & - & - & - & $\begin{array}{l}- \\
-\end{array}$ \\
\hline kitesurfe & - & - & - & - & - & - & - & - & - \\
\hline le parkour [PK] & - & - & - & - & - & - & - & - & - \\
\hline \multirow[t]{2}{*}{ mergulho } & $\mathrm{x}$ & $\mathrm{x}$ & $\mathrm{x}$ & - & $\mathrm{x}$ & $\mathrm{x}$ & $\mathrm{x}$ & - & $\mathrm{x}$ \\
\hline & 1 & 2 & 3 & 4 & 5 & 6 & 7 & 8 & 9 \\
\hline mergulho autônomo, & - & - & - & - & - & $\mathrm{x}$ & $\mathrm{x}$ & - & - \\
\hline
\end{tabular}




\begin{tabular}{|c|c|c|c|c|c|c|c|c|c|}
\hline $\begin{array}{l}\text { m.autônomo } \\
\text { recreativo, } \\
\text { mergulho recreativo, } \\
\text { m. autônomo turístico }\end{array}$ & $\begin{array}{l}- \\
- \\
-\end{array}$ & 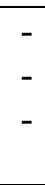 & - & $\begin{array}{l}- \\
- \\
-\end{array}$ & $\begin{array}{l}- \\
- \\
-\end{array}$ & $\begin{array}{l}- \\
- \\
-\end{array}$ & $\begin{array}{l}- \\
- \\
-\end{array}$ & $\begin{array}{l}- \\
-\end{array}$ & $\begin{array}{l}- \\
- \\
-\end{array}$ \\
\hline mergulho em caverna & - & & & & - & - & - & - & - \\
\hline mergulho livre & 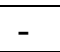 & & & & & - & $\mathrm{x}$ & - & - \\
\hline mergulho noturno & - & 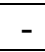 & 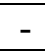 & - & - & - & - & - & - \\
\hline montanhismo & $\mathrm{x}$ & $x$ & 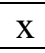 & $\mathrm{x}$ & $\mathrm{x}$ & $\mathrm{x}$ & $\mathrm{x}$ & 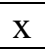 & $\mathrm{x}$ \\
\hline $\begin{array}{l}\text { mountain bike, } \\
\text { mountain biking }\end{array}$ & - & $\begin{array}{l}X \\
-\end{array}$ & - & - & $\begin{array}{l}\mathrm{x} \\
\mathrm{x}\end{array}$ & - & $\begin{array}{l}X \\
-\end{array}$ & - & - \\
\hline muro artificial & - & - & 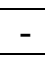 & - & - & - & - & - & - \\
\hline $\begin{array}{l}\text { obs. da vida silvestre, } \\
\text { obs. de vida silvestre, } \\
\text { obs. da vida selvagem, } \\
\text { obs. de fauna e flora }\end{array}$ & $\begin{array}{l}- \\
- \\
-\end{array}$ & - & $\begin{array}{l}- \\
- \\
-\end{array}$ & $\begin{array}{l}- \\
- \\
- \\
-\end{array}$ & $\begin{array}{l}- \\
- \\
-\end{array}$ & $\begin{array}{l}- \\
- \\
-\end{array}$ & $\begin{array}{l}- \\
- \\
- \\
-\end{array}$ & - & - \\
\hline & $\begin{array}{l}- \\
-\end{array}$ & . & - & $\begin{array}{l}- \\
-\end{array}$ & - & - & - & $\begin{array}{l}- \\
-\end{array}$ & - \\
\hline obs. & 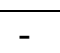 & & & & & - & $\sqrt{1}$ & 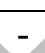 & - \\
\hline paint & - & 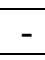 & 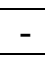 & - & - & - & - & - & - \\
\hline $\begin{array}{l}\text { parap } \\
\text { parag } \\
\text { parag }\end{array}$ & $\begin{array}{l}\mathrm{x} \\
- \\
-\end{array}$ & 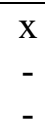 & -1 & - & $\begin{array}{l}- \\
- \\
-\end{array}$ & $\begin{array}{l}x \\
x \\
-\end{array}$ & $\begin{array}{l}\mathrm{x} \\
- \\
\mathrm{x}\end{array}$ & $\begin{array}{l}- \\
-\end{array}$ & $\begin{array}{l}- \\
-\end{array}$ \\
\hline paraquedismo & $\mathrm{x}$ & $\mathrm{x}$ & $\mathrm{x}$ & - & $\mathrm{x}$ & $\mathrm{x}$ & - & - & $\mathrm{x}$ \\
\hline quadriciclo & $\mathrm{x}$ & - & - & - & - & - & - & - & - \\
\hline rafting & $\mathrm{x}$ & - & - & - & $\mathrm{x}$ & $\mathrm{x}$ & $\mathrm{x}$ & - & $\mathrm{x}$ \\
\hline $\begin{array}{lll}\begin{array}{l}\text { rafting em águas } \\
\text { brancas }\end{array} & & \\
\end{array}$ & - & - & - & - & - & - & - & - & - \\
\hline $\begin{array}{l}\text { rapel, } \\
\text { rappel }\end{array}$ & $\begin{array}{l}\mathrm{x} \\
-\end{array}$ & - & $\begin{array}{l}\mathrm{x} \\
-\end{array}$ & $\begin{array}{l}- \\
-\end{array}$ & $\begin{array}{l}\mathrm{x} \\
-\end{array}$ & $\begin{array}{l}- \\
\mathrm{x}\end{array}$ & $\begin{array}{l}\mathrm{x} \\
-\end{array}$ & $\begin{array}{l}- \\
-\end{array}$ & $\begin{array}{l}- \\
\mathrm{x}\end{array}$ \\
\hline remo & $\mathrm{x}$ & $\mathrm{x}$ & 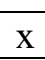 & - & - & - & - & - & $\mathrm{x}$ \\
\hline salto duplo & - & - & - & - & - & - & - & - & - \\
\hline $\begin{array}{l}\text { sandboard, } \\
\text { surfe de areia }\end{array}$ & $\begin{array}{l}- \\
-\end{array}$ & $\begin{array}{l}- \\
-\end{array}$ & $\begin{array}{l}- \\
-\end{array}$ & $\begin{array}{l}- \\
-\end{array}$ & $\begin{array}{l}\mathrm{x} \\
\mathrm{x}\end{array}$ & $\begin{array}{l}- \\
-\end{array}$ & $\begin{array}{l}\mathrm{x} \\
\mathrm{x}\end{array}$ & $\begin{array}{l}- \\
-\end{array}$ & $\begin{array}{l}- \\
-\end{array}$ \\
\hline $\begin{array}{l}\text { skate, } \\
\text { skateboarding, } \\
\text { skateboard, } \\
\text { esqueite }\end{array}$ & $\begin{array}{l}\mathrm{x} \\
- \\
- \\
-\end{array}$ & $\begin{array}{l}- \\
- \\
- \\
-\end{array}$ & $\begin{array}{l}\mathrm{x} \\
- \\
\mathrm{x} \\
\mathrm{x}\end{array}$ & $\begin{array}{l}- \\
- \\
- \\
-\end{array}$ & $\begin{array}{l}- \\
- \\
- \\
-\end{array}$ & $\begin{array}{l}- \\
- \\
- \\
-\end{array}$ & $\begin{array}{l}- \\
- \\
- \\
-\end{array}$ & $\begin{array}{l}- \\
- \\
- \\
-\end{array}$ & $\begin{array}{l}- \\
- \\
- \\
-\end{array}$ \\
\hline skydive & - & - & - & - & - & - & - & - & - \\
\hline $\begin{array}{l}\text { skysurfe, } \\
\text { sky surf, } \\
\text { skysurfing }\end{array}$ & $\begin{array}{l}- \\
- \\
-\end{array}$ & $\begin{array}{l}- \\
-\end{array}$ & $\begin{array}{l}- \\
-\end{array}$ & $\begin{array}{l}- \\
- \\
-\end{array}$ & $\begin{array}{l}- \\
- \\
-\end{array}$ & $\begin{array}{l}- \\
- \\
-\end{array}$ & $\begin{array}{l}- \\
-\end{array}$ & $\begin{array}{l}- \\
- \\
-\end{array}$ & $\begin{array}{l}- \\
-\end{array}$ \\
\hline $\begin{array}{l}\text { snorkeling, } \\
\text { flutuação }\end{array}$ & $\begin{array}{l}- \\
-\end{array}$ & - & $\begin{array}{l}- \\
-\end{array}$ & $\begin{array}{l}- \\
-\end{array}$ & - & $\begin{array}{l}\mathrm{x} \\
-\end{array}$ & $\begin{array}{l}- \\
-\end{array}$ & $\begin{array}{l}- \\
-\end{array}$ & $\begin{array}{l}- \\
-\end{array}$ \\
\hline snov & - & - & - & - & - & - & - & - & - \\
\hline stand up[paddle][SUP] & - & - & - & - & - & - & - & - & - \\
\hline $\begin{array}{l}\text { surfe, } \\
\text { surf }\end{array}$ & $\begin{array}{l}\mathrm{x} \\
\mathrm{x}\end{array}$ & $\begin{array}{l}\mathrm{x} \\
-\end{array}$ & $\mathrm{x}$ & $\begin{array}{l}- \\
-\end{array}$ & $\begin{array}{l}- \\
-\end{array}$ & $\begin{array}{l}- \\
-\end{array}$ & $\begin{array}{l}- \\
-\end{array}$ & $\begin{array}{l}- \\
-\end{array}$ & $\begin{array}{l}\mathrm{x} \\
-\end{array}$ \\
\hline tirolesa & - & - & - & - & - & - & - & - & - \\
\hline $\begin{array}{l}\text { trekking, } \\
\text { caminhada de longo } \\
\text { curso, }\end{array}$ & $\begin{array}{l}x \\
-\end{array}$ & -- & $\begin{array}{l}\mathrm{X} \\
-\end{array}$ & -- & $\begin{array}{l}\mathrm{X} \\
-\end{array}$ & $\begin{array}{l}\mathrm{X} \\
-\end{array}$ & $\begin{array}{l}x \\
-\end{array}$ & - & $\begin{array}{l}x \\
-\end{array}$ \\
\hline
\end{tabular}




\begin{tabular}{|l|c|c|c|c|c|c|c|c|c|}
\hline travessia & - & & - & & - & - & - & & - \\
\hline turismo equestre, & - & - & - & - & $\mathrm{x}$ & $\mathrm{x}$ & - & -- & - \\
cavalgada & $\mathrm{x}$ & $\mathrm{x}$ & $\mathrm{x}$ & - & - & - & $\mathrm{x}$ & & $\mathrm{x}$ \\
\hline tur. fora de estrada, & - & - & - & - & - & - & - & - & - \\
tur. fora-de-estrada, & - & - & - & - & - & - & - & - & - \\
fora de estrada, & $\mathrm{x}$ & - & $\mathrm{x}$ & - & - & - & - & - & - \\
off-road & - & - & $\mathrm{x}$ & - & - & - & - & - & - \\
\hline ultraleve & - & $\mathrm{x}$ & $\mathrm{x}$ & - & $\mathrm{x}$ & - & $\mathrm{x}$ & - & - \\
\hline vela & - & - & $\mathrm{x}$ & - & - & - & - & - & $\mathrm{x}$ \\
\hline via ferrata & - & - & - & - & - & - & - & - & - \\
\hline voo livre, & - & - & $\mathrm{x}$ & - & $\mathrm{x}$ & $\mathrm{x}$ & $\mathrm{x}$ & - & $\mathrm{x}$ \\
\hline wakeboard & - & - & - & - & - & - & - & - & - \\
\hline windsurfe, & $\mathrm{x}$ & $\mathrm{x}$ & $\mathrm{x}$ & - & - & - & $\mathrm{x}$ & - & $\mathrm{x}$ \\
prancha a vela & - & - & $\mathrm{x}$ & - & - & - & - & - & - \\
\hline
\end{tabular}

A primeira coluna foi destinada aos termos principais organizados em ordem alfabética, acrescidos de suas variantes, e as colunas seguintes destinadas a cada uma das fontes consultadas. Na obra 6, alguns termos não configuravam como entrada, mas eram mencionados dentro do verbete de outro termo e, por isso, foram considerados registrados.

Uma vez apresentado o levantamento da codificação lexicográfica e terminográfica dos termos, passemos à análise dos dados.

\section{Análise dos dados}

Retomando a observação de Estornell Pons (2013), uma parte do acervo lexical que estamos estudando são palavras assentadas na língua comum e codificadas lexicograficamente, visto que nomeiam esportes e atividades físicas praticadas já há algum tempo.

Verificamos que dos 130 termos levantados (75 termos principais e 55 variantes), 45 deles, aproximadamente $34,6 \%$, estavam registrados em pelo menos uma das três obras de língua geral. ${ }^{6}$

Contrariando nossas expectativas, a porcentagem de registros no caso das obras especializadas na área do turismo continuou praticamente a mesma, com um leve acréscimo. Verificamos que estavam registrados em pelo menos uma das seis obras apenas 46 dos termos levantados, aproximadamente 35,4\%. A nosso ver, isso ocorreu porque o subcampo das atividades esportivas e recreativas é apenas um dos componentes do domínio do turismo, dividindo o enfoque das obras especializadas em turismo com termos de outros campos

\footnotetext{
${ }^{6}$ Os termos com duas acepções foram contados duas vezes.
} 
nocionais. Isso também nos fez perceber que esse subcampo não tem sido devidamente explorado e atualizado pelas obras do gênero, justificando ainda mais nosso trabalho de levantamento e tratamento dessas unidades.

Dentre os termos não encontrados em nenhuma das obras, estão: acqua-ride (acqua ride); base jump; big wall (escalada em big wall); bodyboard; bodysurfe (bodysurf); boulder (escalada de bloco, bouldering, escalada em bloco); cachoeirismo (cascading); caiaque surfe, surf kayak; caiaque turístico (kayaktouring); canionismo; canoagem oceânica (caiaque oceânico, seakayak); corrida de aventura; corrida de orientação (orientação); duck (caiaque inflável); escalada artificial; escalada em rocha; escalada esportiva; espeleoturismo (caving, cavernismo); espeleoturismo vertical; hidrospeed; kitesurfe; le parkour; mergulho autônomo recreativo (mergulho recreativo, mergulho autônomo turístico); mergulho em caverna; mergulho noturno; muro artificial; observação da vida silvestre (observação de vida silvestre, observação da vida selvagem); observação de aves (observação de pássaros); observação de baleias; paintball; salto duplo; skateboarding; skydive; skysurfe (sky surf, skysurfing); flutuação; snowboard; stand up; tirolesa; caminhada de longo curso (travessia); turismo fora de estrada (turismo fora-de-estrada); via ferrata; wakeboard.

O fato de mais da metade dos termos não estar registrada nas obras analisadas pode ser atribuído a diferentes fatores: termos que designam atividades de criação mais recente ou atividades de menor interesse turístico; termos provenientes de outras línguas, com diferentes níveis de adaptação, ainda em processo de assimilação pela língua vernácula; variantes menos utilizadas; o critério e corpora adotados para a seleção dos termos e, principalmente, a falta deles; termos que designam subtipos de uma atividade, com maior nível de especialização e dificuldade, como é o caso de modalidades especiais de escalada ou mergulho e de atividades mais radicais, o que diminui a chance de serem incluídos tanto em obras de língua geral, que trazem as atividades de modo mais genérico, quanto em obras especializadas em turismo, visto que os turistas, em sua maioria, não são atletas, realizando geralmente atividades de menor risco.

A respeito da ausência de registro lexicográfico, Manzolillo (2001, p. 13) defende que esse "é um fato irrelevante, podendo ou não vir a ocorrer no futuro" e que "a aceitação dos falantes, no entanto, já é um fato real e presente. Saber se um item lexical 'existe' não é preocupação primordial dos usuários de um idioma, que, no dia-a-dia, estão mais interessados em comunicar ideias e em transmitir pensamentos". Sendo assim, embora não estejam 
registrados em nenhuma das obras selecionadas, há termos muito frequentes no corpus de turismo de aventura e que denominam atividades que já estão bem consolidadas na área do turismo. Vejamos alguns contextos:

As atividades mais ofertadas no país são: Caminhada (oferecida por 741); Rapel (oferecido por 392); Turismo Equestre (oferecido por 342) e Tirolesa (oferecida por 308 organizações). Além dessas, foram encontradas 158 ofertantes de Acquaride/Bóia-cross; 295 que oferecem Arvorismo; 41 de Balonismo; 32 de Bungee Jump; 137 oferecem Caminhada de Longo Curso; 227 de Canionismo/Cachoeirismo; 208 de Canoagem; 218 de Cicloturismo; 259 oferecem Escalada; 103 oferecem Espeleoturismo; 134 oferecem Flutuação (incluindo Snorkeling); 157 oferecem Kitesurfe; 273 oferecem Mergulho; 247 ofertantes de Observação da Vida Silvestre; 117 oferecem Paraquedismo; 123 oferecem Quadriciclo; 248 oferecem Rafting/Duck; 171 oferecem Surfe; 249 oferecem Turismo Fora-de-Estrada com Veículos 4x4; 93 ofertam Turismo Fora-de-Estrada com Bugues; 225 de Voo Livre e 109 oferecem Windsurfe. (BRASIL; ASSOCIAÇÃO BRASILEIRA DE EMPRESAS DE ECOTURISMO E TURISMO DE AVENTURA, 2011, p. 39, grifo nosso)

O Stand up, por exemplo, atividade que mescla canoagem com surfe, em que o turista rema em pé em cima de uma prancha, tem atraído adeptos no Brasil, principalmente no litoral de São Paulo e do Rio de Janeiro. (BRASIL; ABETA, 2011, p. 49, grifo nosso) ${ }^{7}$

A tirolesa é uma atividade de aventura originária da região do Tirol, na Áustria. Consiste em um cabo aéreo ancorado horizontalmente entre dois pontos, pelo qual o aventureiro se desloca através de roldanas conectadas por mosquetões a uma cadeirinha de alpinismo. Tal atividade permite ao praticante a emoção de voar por vales contemplando belas paisagens. (BRASIL, 2009, p. 41, grifo nosso)

Tanto que as atividades de aventura na natureza são divididas de acordo com os ambientes físicos em que são praticadas. Nos ambientes: terra, sobre um meio estável e curso bidimensional (vertical e horizontal) - skateboard, snowboard, montainbike, esqui acrobático, escalada livre, - água, meio instável e curso bidimensional - surf, hidrospeed, rafting, cascading - e ar, meio instável e curso tridimensional - rope swing, queda livre em pára-quedas, asa delta, parapente, bungee jump. (BETRÁN; BETRÁN, 2006 apud CÁSSARO, 2011, p. 17).

\footnotetext{
${ }^{7}$ Embora não tenha ocorrido em nosso corpus, observamos em outras fontes a ocorrência do termo stand up paddle, do inglês stand up paddling, e de sua forma abreviada SUP, que foram introduzidos em nossa lista de termos entre colchetes. O mesmo ocorreu com a sigla $P K$, abreviação de le parkour.
} 
À medida que novas atividades ou variações delas vão sendo criadas ou trazidas de outros países para o Brasil, ocorrendo geralmente o segundo caso, esse acervo terminológico se renova e amplia.

Conforme observa Alves (2006, p. 32), “de maneira geral, a renovação lexical - ou neologia terminológica (6) - nos domínios de especialidade segue os mesmos processos que presidem à formação de palavras no léxico geral, não-especializado". ${ }^{8}$ Sendo assim, “de maneira análoga aos neologismos da língua geral, os neologismos terminológicos são formados pelos processos vernaculares da derivação, da composição, da transferência semântica, das formações sintagmáticas, da redução e pelo empréstimo de outros idiomas" (ALVES, 2006, p. 32). O conjunto terminológico aqui analisado comprova a observação de Alves (2006), pois nele identificamos variados processos de formação de termos.

Visto que a análise que faremos desses processos não está estruturada em forma de tópicos específicos, mas construída de forma contínua, em que um aspecto entrelaça-se e leva a outro, apresentamos, na sequência, as questões que se destacaram e serão examinadas adiante: empréstimos de outros idiomas, notadamente os anglicismos; as variações decorrentes da entrada de empréstimos; criação em língua vernácula a partir de formantes estrangeiros; a produtividade do sufixo -ismo; criação de termos a partir da palavra turismo e dos adjetivos turístico ou recreativo; processos metonímicos e processos sintagmáticos.

Em relação à primeira questão, iniciemos com a diferenciação entre empréstimo externo e interno feita por Alves (1995, p. 319-320): o primeiro é o "empréstimo de termo de uma outra língua", e o segundo, "o empréstimo efetuado no âmbito de uma mesma língua, por meio da passagem desse termo a um outro domínio, a um outro registro de língua, ou ainda da língua geral a uma língua de especialidade". No conjunto terminológico sob estudo, ocorreram apenas os empréstimos do primeiro tipo.

Assim como em outros domínios de especialidade, a adoção de empréstimos externos, principalmente da língua inglesa, é um traço marcante da terminologia do turismo e ocorre de forma algo especial no campo das atividades esportivas e recreativas. Moreira (2010, p. 513), em seu estudo para criação de uma base de dados terminológica do turismo em português europeu e inglês, constatou que "a grande maioria dos empréstimos, na sua quase totalidade anglicismos, surgem, sobretudo, no campo temático 'Actividades desportivas e recreativas"”.

\footnotetext{
${ }^{8} \mathrm{O}$ número (6) refere-se a uma nota feita por Alves (2006, p. 34) na qual informa que o neologismo terminológico é chamado de neônimo por Rondeau (1984, p. 121) e de neotermo por Boulanger (1989, p. 202).
} 
Nossos dados corroboram os dois apontamentos feitos por Moreira (2010). De fato, no campo das atividades ocorrem muitos empréstimos, e destacam-se aqueles provenientes da língua inglesa, observando-se variados graus de adaptação morfológica e/ou fonológica. As exceções são: le parkour e rappel, do francês, e via ferrata, do italiano.

Em nosso corpus, observamos a ocorrência de termos incorporados sem qualquer alteração morfológica, tais como hiking, snorkeling, trekking, rafting, le parkour, via ferrata. Também observamos que, ao serem incorporados, vários termos emprestados do inglês tem o sufixo -ing suprimido, como em: base jump, boulder, stand up [paddle], body-board (bodyboard), sandboard, wakeboard, jet ski, bungee jump, mountain bike, skate. E outros termos já sofreram adaptações parciais à língua portuguesa, tais como bodysurfe, kitesurfe e windsurfe, em que o primeiro elemento preserva a forma e pronúncia da língua inglesa, e o segundo elemento passa por um processo de adaptação morfológica e fonológica; e outros foram totalmente adaptados, tais como surfe, esqui e rapel.

Maia (1975 apud FERREIRA, 1975, p. vii), ao prefaciar o Dicionário Brasileiro de Turismo, já apontava o Turismo como uma "área em que a velocidade de ingresso de novos termos tende a exceder a capacidade de absorção e transformação de nossa língua". Carvalho (2009, p. 80) aborda essa relação velocidade versus capacidade de absorção, explicando que "a cunhagem de um novo termo demànda tempo e interesse, enquanto a adoção é instantânea". Segundo o prognóstico de Maia (1975 apud FERREIRA, 1975), com o passar do tempo, os neologismos diversos ou encontrariam substituto natural na língua portuguesa de uso corrente ou permaneceriam como vieram, aportuguesados pelo emprego continuado.

Uma hipótese, entretanto, não exclui necessariamente a outra, e nesse processo observase a concorrência, em diferentes graus e formas, entre o(s) termo(s) emprestado(s) sem adaptações, o(s) termo(s) criado(s) em língua vernácula e o(s) termo(s) a ela adaptado(s) ou traduzido(s). Os exemplos no corpus são abundantes e variados: espeleoturismo/cavernismo e caving; canionismo e canyoning; caiaque oceânico/canoagem oceânica e seakayak; caiaque surfe e surf kayak; caiaque turístico e kayaktouring; duck e caiaque inflável; snorkeling e flutuação; windsurfe e prancha a vela; parapente e paraglider/paragliding; caminhada e hiking; caminhada e trekking; boulder/bouldering e escalada de bloco/escalada em bloco; sandboard e surfe de areia; skate/skateboarding/skateboard e esqueite; turismo fora de estradalturismo fora-de-estradalfora de estrada e off-road/off road; bodyboard/bodyboard/bodyboarding; mountain bike/mountain biking. 
Esse movimento contínuo de entrada de termos estrangeiros, adaptações (parciais, totais) e/ou traduções traz como resultado um conjunto terminológico marcado pela variação (ortográfica, lexical etc). No caso dos anglicismos, isso decorre tanto do processo de assimilação pela língua portuguesa (com ou sem -ing) quanto da variação ortográfica existente na própria língua inglesa (com hífen, sem hífen ou justaposição sem hífen).

A influência da língua inglesa se faz presente até mesmo no processo de criação autóctone. Vejamos os casos de acqua-ride, boia-cross e cascading. Em um primeiro momento, pensamos tratar-se de termos de origem inglesa. Contudo, essas unidades não foram encontradas no Corpus de Turismo de Aventura em Inglês (CTAI) e tampouco em dicionários de língua inglesa. Verificamos, a posteriori, que os termos acqua-ride e boia-cross, frequentemente usados como sinônimos, designam uma atividade tipicamente brasileira, originada da prática de descer rios em câmaras de ar de pneus, hoje já realizada com equipamentos especiais. Embora se trate de termos que designam uma atividade muito praticada no turismo de aventura, a primeira forma não está registrada em nenhuma das obras consultadas, e a segunda aparece em apenas duas das seis obras especializadas em turismo.

O Bóia-Cross, também conhecido como “acqua ride”, surgiu na década de 1970 no Brasil com a velha brincadeira de descer um rio com correnteza em câmaras de ar de pneus de automóveis. (FIGUEIREDO; CAMPOS, 2007, p. 109, grifo nosso)

No bóia-cross este participante deverá ter as pernas cruzadas à frente (posição de índio), no Acqua-ride, o participante deverá deitar-se de bruços e manter as pernas dentro d'água, mantendo a estabilidade da bóia. (BRASIL, 2009, p. 69, grifo nosso)

O outro termo, cascading, designa uma atividade também conhecida como cachoeirismo, que consiste em fazer rapel em uma cachoeira. O termo cascading, formado a partir da junção da palavra cascade com o sufixo inglês -ing, não foi encontrado no CTAI e tampouco em dicionários de língua inglesa, levando-nos a conclusão de que, apesar da aparência anglófona, trata-se também de um termo criado no Brasil. Apesar disso, verificamos que os termos cascading e cachoerismo não estão registrados em nenhuma das obras consultadas, mesmo o segundo sendo formado por meio do sufixo -ismo, muito produtivo em língua portuguesa para formar palavras que designam atividades físicas.

Embora nosso foco seja a língua portuguesa, comentemos um caso semelhante referente à língua espanhola. Para se referir à atividade em que o participante salta de uma ponte preso pelos pés a uma corda elástica, em inglês bungee jumping, em português bunguee jump, 
encontramos com grande frequência no Corpus de Turismo de Aventura em Espanhol (CTAE) o termo puenting, um hibridismo formado pela junção da palavra espanhola puente com o sufixo inglês -ing. A título de curiosidade, mencionemos que em algumas obras, como o Diccionario Panhispánico de Dudas da Real Academia Española (2005) e o dicionário online Clave, condena-se o uso do hibridismo puenting, apontado como desnecessário, recomendandose a adaptação patrimonial puentismo, formado por meio do sufixo -ismo.

O sufixo -ismo também é muito produtivo na formação de palavras que denominam as atividades físicas em língua portuguesa. Dentre os termos formados por ele e registrados tanto nas obras de língua geral quanto nas especializadas, citamos: alpinismo, balonismo, ciclismo, montanhismo e paraquedismo, todos relativos a atividades mais tradicionais. Também foram encontrados no corpus os temos arvorismo (arborismo), canionismo, cavernismo $e$ cachoeirismo, este último já comentado. Interessante notar que o termo arvorismo (arborismo), referente à locomoção por percursos instalados em árvores e outras estruturas altas, apesar de muito frequente no CTAP, está registrado em apenas uma das obras de língua geral, não tendo registro em nenhuma das seis obras de turismo analisadas. Os termos seguintes, canionismo e cavernismo, a exemplo de cachoeirismo, também não apresentam registro em nenhuma das obras verificadas, o que reforça o caráter de novidade dessas unidades. A primeira atividade, canionismo, consiste em seguir o percưrso traçado por um curso d'água no interior de um cânion sem uso de embarcação e com transposição de obstáculos horizontais e verticais, a segunda, cavernismo, refere-se a atividades de observação e recreação desenvolvidas em cavernas.

Essa segunda atividade também pode ser designada pelo termo espeleoturismo, no qual podemos observar outro processo de formação cada vez mais recorrente no domínio do Turismo. Esse termo é formado a partir do lexema base turismo acrescido do formante culto espeleo-(caverna). Para destacar o caráter de novidade desse termo, recorreremos novamente a um exemplo da língua espanhola. Em espanhol, o termo espeleología, encontrado no CTAE, é usado para se referir tanto ao estudo científico quanto à prática de exploração de cavernas, vejamos a definição de espeleología no dicionário online Clave:

\section{espeleología}

1 Deporte que consiste en la exploración de cavidades naturales subterráneas: $\mathrm{He}$ comprado unas cuerdas especiales para practicar espeleología.

2 Ciencia que estudia La naturaleza, origen y formación de las cavernas, así como su fauna y su flora: La espeleología estudia las cavidades naturales de la superfície terrestre. 
Em português, apesar de dispormos do termo espeleologia para nos referirmos ao estudo científico, no âmbito do Turismo, foi criado um termo novo, espeleoturismo, para se referir à vertente com fins recreativos, dando-lhe ênfase enquanto um produto turístico. Vejamos as definições desses termos:

\section{espeleologia}

1 Rubrica: geologia.

estudo da formação e constituição de grutas e cavernas naturais; espeologia, espeluncologia. (HOUAISS, 2009)

espeleoturismo: Atividades desenvolvidas em cavernas, oferecidas comercialmente, em caráter recreativo e de finalidade turística. (ASSOCIAÇÃO BRASILEIRA DE NORMAS TÉCNICAS, 2006, p. 1)

Outro termo formado pelo mesmo processo e motivação é cicloturismo, a partir do lexema base turismo acrescido do formante culto ciclo. Também se trata de um termo criado no âmbito do turismo, apesar da existência do termo ciclismo. Comparemos as definições:

\section{ciclismo}

1 arte ou exercício de andar de bicicleta como meio de locomoção ou como passatempo (HOUAISS, 2009)

Atividades ciclísticas - percurso em vias convencionais e não convencionais em bicicletas, também denominadas de cicloturismo. (BRASIL, 2009, p. 34)

cicloturismo: atividade de turismo que tem como elemento principal a realização de percursos com o uso de bicicleta [...] (ASSOCIAÇÃO BRASILEIRA DE NORMAS TÉCNICAS, 2007, p. 2).

O termo espeleoturismo não está registrado em nenhuma das obras, e cicloturismo está registrado em apenas uma obra especializada.

Nessa mesma linha, encontram-se os termos turismo fora-de-estrada e turismo equestre, com a diferença de serem formados por um processo sintagmático, tendo como núcleo a palavra turismo.

Foram encontradas no corpus as formas: fora de estrada, off road, turismo-fora-deestrada e turismo fora de estrada. Nas obras consultadas, foram encontradas apenas as formas fora de estrada e off-road: 


\section{fora de e.}

Regionalismo: Brasil.

que ou o que foi projetado para andar fora das estradas (diz-se de veículo automotor) (HOUAISS, 2009)

\section{off-road}

adjetivo de dois gêneros e dois números e substantivo masculino de dois números Rubrica: automobilismo.

ver fora de estrada (HOUAISS, 2009)

A forma turismo fora-de-estrada (com e sem hífen) foi encontrada apenas no corpus, com um sentido mais especializado:

turismo fora-de-estrada: Atividade de turismo que tem como elemento principal a realização de percursos em vias não-convencionais com veículos automotores. NOTA O percurso pode incluir trechos em vias convencionais (ASSOCIAÇÃO BRASILEIRA DE NORMAS TÉCNICAS, 2006, p. 1).

O mesmo ocorre com o termo turismo equestre, encontrado no corpus e registrado apenas em duas das obras de turismo:

\section{turismo eqüestre}

atividade turística oferecida comercialmente, onde o eqüino ou muar é o meio de transporte e um dos principais atrativos (ASSOCIAÇÃO BRASILEIRA DE NORMAS TÉCNICAS, 2008a, p. 2)

No que se refere às atividades de Turismo de Aventura podem ocorrer no contexto de outros segmentos agregando-lhes atratividade e valor ao produto. Exemplificando: caminhadas, turismo equestre (passeios a cavalo), cicloturismo, arvorismo podem fazer parte tanto do Turismo Rural, do Ecoturismo e do Turismo de Aventura. (BRASIL, 2010b, p. 63, grifo nosso)

\section{Cavalgadas}

Percursos em vias convencionais e não convencionais em montaria, também tratadas de Turismo Equestre. (BRASIL, 2010b, p. 18, grifo nosso)

Antes de passarmos para o próximo caso, é interessante notar que os termos off-road e fora-de-estrada são adjetivos usados com valor substantivo. Ao termo fora-de-estrada, posteriormente, foi acrescido o substantivo turismo, formando o termo sintagmático turismo fora-de-estrada. Geralmente, costuma ocorrer o contrário: o substantivo é suprimido e o adjetivo que o determina, por um processo de conversão (derivação imprópria), passa a ser 
usado na função de substantivo, como exemplifica Manzolillo (2001, p. 16): "jogar na esportiva equivale a jogar na loteria esportiva".

Outro processo recorrente para se enfatizar o caráter lúdico de uma atividade é o acréscimo dos adjetivos recreativo ou turístico ao termo que a designa, como é o caso do termo mergulho autônomo (mergulho praticado com o auxílio de equipamentos que permitem a respiração submersa) e caiaque (percurso aquaviário em embarcação, geralmente fechada, em que o turista permanece sentado e utiliza remo de duas pás). No corpus, encontramos esses termos acrescidos dos adjetivos citados. Vejamos:

As normas internacionais para mergulho autônomo recreativo especificam três níveis de treinamento e certificação de mergulhadores autônomos e dois níveis de treinamento e certificação de instrutores de mergulho autônomo. (BRASIL, 2008b, p. v, grifo nosso)

Como lazer, o mergulho recreativo (com usos de equipamentos de respiração autônoma) é praticado no Brasil há mais de 30 anos e foi trazido por interessados que faziam cursos em outros países. (BRASIL; ASSOCIAÇÃO BRASILEIRA DE EMPRESAS DE ECOTURISMO E TURISMO DE AVENTURA, 2011, p. 52, grifo nosso)

mergulho autônomo turístico (produto turístico): produto em que a atividade principal é o mergulho autônomo e o praticante não é necessariamente um mergulhador qualificado.” (ASSOCIAÇÃO BRASILEIRA DE NORMAS TÉCNICAS, 2007, p. 3, grifo do autor).

Há uma diversidade de atividades na modalidade de canoagem. Entre elas o caiaque oceânico (seakayak) ou caiaque turístico (kayaktouring), para se realizar viagens de um dia ou mais, tanto em águas abrigadas ou abertas. (BRASIL; ASSOCIAÇÃO BRASILEIRA DE EMPRESAS DE ECOTURISMO E TURISMO DE AVENTURA, 2011, p. 48, grifo nosso)

Seja por estratégia de marketing ou pela necessidade de dar um diferencial a uma atividade já existente, destacando-a como um produto turístico, a formação de termos a partir da palavra turismo ou dos adjetivos recreativo ou turístico é cada vez mais recorrente na área do Turismo, e isso também é observado em outras línguas: em espanhol, cicloturismo; turismo ecuestre; buceo recreativo, buceo de recreo; piragüismo recreativo, piragüismo turístico, piragüismo de recreo; em inglês, recreational caving; cycletouring, recreational biking, recreational cycling, cycletourism; off-road tour; equestrian tourism, horse riding tourism, 
recreational horseriding, recreational horseback riding; recreational scuba diving, recreational diving. ${ }^{9}$

Segundo Manzolillo (2001, p. 17), "muitas vezes, a novidade - seja ela de que tipo for - não surge para nomear um referente inédito. Um sinônimo pode ser criado - ou adotado justamente para que se possam vencer os desgastes naturais das palavras, comunicando velhas coisas de novas maneiras".

Outro traço característico dessa terminologia, também assinalado por Estornell Pons (2013, p. 37), refere-se ao fato de certas atividades serem designadas pelos mesmos termos que nomeiam o equipamento utilizado para sua prática, ou seja, por meio de um processo metonímico. No corpus, temos os casos de: arco e flecha, asa-delta, canoa, caiaque, duck, esqui,jet ski, muro artificial, parapente, prancha a vela, quadriciclo, remo e ultraleve. Vejamos um contexto e definição do termo parapente:

Quanto às atividades de Turismo de Aventura realizadas no ar, podem ser exemplificadas por intermédio do pára-quedismo, do parapente, do balonismo, do ultraleve, da asa delta, entre outras. (WIDMER et al., 2010, grifo nosso)

\section{parapente}

1 aparelho esportivo idealizado de uma mistura de asa-delta e paraquedas, com o qual se salta de uma elevação para descer planando

2 Derivação: por metonímia.

esporte praticado com esse aparelho (HOUAISS, 2009)

Os domínios de especialidade caracterizam-se também pela criação de termos de tipo sintagmático, "produção neonímica com base em oposições distintivas entre unidades terminológicas que têm como lexema-base um hiperônimo (termo mais genérico)" (BARROS, 2004, p. 101). Segundo Alves (2006, p. 33), essas formações têm significado em geral transparente, constituindo segmentos de frase que se lexicalizam e tornam-se novas unidades do léxico e tendem a seguir uma estrutura em que um termo determinado é expandido por um adjetivo ou sintagma preposicional também passível de ser expandido.

Esse é o caso, por exemplo, dos termos formandos a partir do lexema-base observação, tais como: observação da vida silvestre (observação de vida silvestre, observação da vida

\footnotetext{
${ }^{9}$ Piragüismo (canoagem), buceo (mergulho), caving (espeleoturismo, cavernismo), cycling/biking (ciclismo), horse riding (passeio a cavalo), off-road (fora-de-estrada), scuba diving (mergulho autônomo).
} 
selvagem, observação de fauna e flora), observação de aves (observação de pássaros $)^{10} \mathrm{e}$ observação de baleias. Abaixo seguem contextos de ocorrência desses termos:

\subsection{Observação da Vida Silvestre}

Prática de observar uma área natural ou especificamente algum ou alguns de seus elementos como as aves e os mamíferos. [...] A crescente conscientização ecológica, que implica a preservação de áreas naturais, propicia o fomento dessa atividade de observação, cujas subdivisões são: observação de aves (birdwatching ou birding), observação de baleias (whalewatching) [...] (BRASIL; ASSOCIAÇÃO BRASILEIRA DE EMPRESAS DE ECOTURISMO E TURISMO DE AVENTURA, 2011, p. 67)

O cenário propicia um ambiente ideal para o Ecoturismo e o Turismo de Aventura, podendo ser desenvolvidas atividades diversas, como a observação de pássaros, trilhas, acampamento e atividades náuticas. (BRASIL; ASSOCIAÇÃO BRASILEIRA DE EMPRESAS DE ECOTURISMO E TURISMO DE AVENTURA, 2011, p. 114)

Segundo Krieger e Finatto (2004, p. 81), a tendência à composição sintagmática é um traço peculiar às terminologias. Para delimitar um termo sintagmático é importante conhecer os critérios ${ }^{11}$ que podem ser utilizados e combinados para diferenciar desde um simples segmento de frase até um segmento frásico lexicalizado, que, segundo Alves (1999, p. 73), “[...] se tornou (ou está se tornando) um novo termo". Dentre eles, os que nos auxiliaram na identificação dos termos acima foram principalmente: a frequência de coocorrências, conforme pode ser observado nas linhas de concordância expostas na Fig. 1, e a existência de uma definição especializada, conforme pode ser observado no contexto definitório do termo observação da vida silvestre (também definido em uma das seis obras de turismo analisadas na pesquisa). Segundo Barros (2004, p. 103; 105), esses são alguns dos critérios que podem ser usados para avaliar o graú de lexicalização de um termo sintagmático.

Em nossa pesquisa, notamos que grande parte dos termos sintagmáticos, que expressam geralmente um conceito mais especializado, não estava registrada nas obras consultadas, tais como os termos formados a partir dos lexemas-base escalada, mergulho, caiaque etc. Como já consignamos, quanto maior o grau de especialidade, menor a probabilidade de estarem

\footnotetext{
${ }^{10}$ Pássaro é definido como "ave pequena; passarinho [...] design. comum às aves da ordem dos passeriformes" (HOUAISS, 2009). Portanto, o termo observação de aves é mais abrangente do que observação de pássaros, este último apenas com uma ocorrência no corpus. Entretanto, o termo foi selecionado, pois, pensando-se na elaboração de um dicionário especializado, julgamos importante fazer essa distinção ao leitor.

${ }^{11}$ Para um estudo mais detalhado desses critérios, consultar Alves (1999) e Barros (2004).
} 
registrados em obras de língua geral ou mesmo em obras especializadas em turismo, visto que os turistas, em sua maioria, praticam atividades de menor risco e complexidade.

\section{Considerações finais}

Este artigo teve como objetivo analisar um conjunto de termos que designam atividades esportivas e recreativas desenvolvidas no turismo de aventura no que se refere à inovação lexical nesse domínio, tendo com um dos parâmetros norteadores a verificação de seu registro em dicionários de língua geral e especializados, buscando também oferecer um panorama geral dessa terminologia. Observamos que mais da metade dos termos analisados não estava registrada nas obras de língua geral e que, contrariando nossas expectativas, essa quantidade permaneceu praticamente a mesma, com um leve acréscimo, em relação às obras especializadas em turismo, fato que atribuímos a vários fatores: alto nível de especialização dos termos, critério de seleção para seleção dos termos e corpus utilizado, velocidade de criação de termos, termos emprestados de outras línguas e em processo de assịmilação pela língua vernácula, dentre inúmeros outros. Contudo, a verificação da existência ou ausência de registro do termo não foi o ponto central, mas apenas um subsídio para demonstrar a dinamicidade desse acervo terminológico e o intenso movimento de renovação e ampliação lexical existente nessa área. Dentre os processos de renovação lexical observados, destacamos o empréstimo externo, notadamente aqueles provenientes da língua inglesa; criações em língua vernácula a partir de formantes da língua inglesa; a produtividade do sufixo -ismo; a criação de termos a partir do lexema-base turismo e dos adjetivos turístico ou recreativo, como forma de dar uma nova aparência a um conceito já existente; processos metonímicos, por meio dos quais designa-se a atividade com o nome do equipamento usado para praticá-la e processos sintagmáticos, por meio da lexicalização de segmentos de frases que designam conceitos específicos dentro de um domínio de especialidade.

\section{Referências bibliográficas}

ALVES, I. M. Empréstimos nas línguas de especialidade: algumas considerações. Ciência da Informação, Brasília, v. 24, n. 3, 1995, pp. 319-321.

. A delimitação da unidade lexical nas línguas de especialidade. Palavra. Rio de Janeiro: Grypho, 1999, v. 5, pp. 69-80. 
A renovação lexical nos domínios de especialidade. Cienc. Cult. [online]. 2006, vol.58, n.2, pp. 32-34.

ARAGÓN COBO, M.; EURRUTIA CAVERO, M.; PLANELLES IBÁNEZ, M. El lenguaje del turismo. In: ALCARAZ VARÓ, E.; MATEO MARTÍNEZ, J.; YUS RAMOS, F. (eds.). Las lenguas profesionales y académicas. Barcelona: Ariel, 2007. p. 233-245.

ASSOCIAÇÃO BRASILEIRA DE NORMAS TÉCNICAS. NBR 15399: Turismo de aventura - Condutores de espeleoturismo de aventura - Competências de pessoal. Rio de Janeiro, 2006.

NBR 15500: Turismo de aventura - Terminologia. Rio de Janeiro, 2007.

. NBR 15507-1: Turismo equestre - Parte 1: Requisitos para produto. Rio de Janeiro, $2008 \mathrm{a}$.

NBR ISO 24803: Serviços de mergulho recreativo - Requisitos para prestadores de serviços de mergulho autônomo recreativo. Rio de Janeiro, 2008b.

BARBOSA, M. A. Língua e discurso: contribuição aos estudos semântico-sintáticos. São Paulo: Global, 1978.

BARROS, L. A. Curso básico de Terminologia. São Paulo: Edusp, 2004.

BERBER SARDINHA, Tony. Usando Wordsmith Tools na investigação da linguagem. DIRECT Papers 40, 1999. Disponível em:<http://www2.lael.pucsp.br/direct/Direct Papers40.pdf. $>$. Acesso em: 04 dez. 2015.

BETRÁN, A. O.; BETRÁN, J. O. Propuesta de una clasificación taxonómica de las actividades físicas de aventura en la natureza. Marco conceptual y análisis de los critérios elegidos In.: Dossier Las Actividades Físicas de Aventura en la Naturaleza: análisis sociocultural. Apunts: Educación Física y Deportes, Barcelona: Institut Nacional d'Educación Física de Catalunya, n. 41, p. 5-8, jul. 1995.

BRASIL. Ministério do Turismo. Regulamentação, normatização e certificação em turismo de aventura: relatório diagnóstico. Brasília: Ministério do Turismo, 2005.

2006.

Segmentação do Turismo: Marcos Conceituais. Brasília: Ministério do Turismo,

Diagnóstico do Turismo de Aventura no Brasil. Brasília: Ministério do Turismo, 2008 .

Turismo Acessível: bem atender no turismo de aventura adaptada. Volume IV. Brasília: Ministério do Turismo, 2009.

. Ecoturismo: orientações básicas. 2. ed. Brasília: Ministério do Turismo, 2010a.

. Turismo de Aventura: orientações básicas. Brasília: Ministério do Turismo, 2010b. 
; ASSOCIAÇÃO BRASILEIRA DE EMPRESAS DE ECOTURISMO E TURISMO DE AVENTURA. Relatório de Impactos do Programa Aventura Segura. Belo Horizonte: ed. dos autores, 2011.

BUCKLEY, R.; UVINHA, R. R. Turismo de Aventura: Gestão e Atuação Profissional. Rio de Janeiro: Elsevier, 2011.

CARVALHO, N. Empréstimos linguísticos na língua portuguesa. São Paulo: Cortez, 2009.

CÁSSARO, E. R. Atividades de aventura: aproximações preliminares na rede municipal de ensino de Maringá. Especialização em Educação Física. Universidade Estadual de Londrina. Londrina, 2011.

CLAVE. Diccionario de uso del Español actual. Disponível em: <http://clave.sm diccionarios.com/app.php>. Acesso em: 26 set. 2015.

ESTORNELL PONS, M. Aproximación al léxico del turismo activo: codificación lexicográfica, formación y variación denominativa. Revista de estudios lingüísticos hispânicos, 2013, n. 3, p. 33-35.

FUNOLLET, F. Propuesta de clasificación de las actividades deportivas en el medio natural. Apunts- Educación física y deportes, 1995, n. 41, p. 124-129.

FERREIRA, F. L. V. Dicionário Brasileiro de Turismo. Rio de Janeiro: Colorama, 1975.

FIGUEIREDO, J. de P. Atitudes de condutores de atividades de aventura e a perspectiva de disseminação da sensibilização ambiental. 154 f.: il., gráfs.,tabs., fots. Dissertação (Mestrado) - Universidade Estadual Paulista, Instituto de Biociências de Rio Claro, 2012.

FIGUEIREDO, L. G. B.; CAMPOS, J. G. C. Turismo de esportes e aventura: livro didático. 3. ed. Palhoça: Unisul Virtual, 2007.

HOUAISS, A. Dicionário Houaiss eletrônico da língua portuguesa. Rio de Janeiro: Objetiva, 2009.

IGNARRA, L. R. Fundamentos do turismo. 2. ed. São Paulo: Thomson, 2003.

KRIEGER, M. da G.; FINATTO, M. J. B. Introdução à terminologia: teoria e prática. São Paulo: Contexto, 2004.

LOHMANN, G.; PANOSSO NETTO, A. Teoria do Turismo: conceitos, modelos e sistemas. Aleph: São Paulo, 2012.

MANZOLILLO, V. C. de O. Acerca da dinamicidade lexical. SOLETRAS, ano I, n. 02. São Gonçalo: UERJ, jul./dez. 2001. 
MAIA, O. L. Prefácio. In: FERREIRA, Fernando Luiz Vieira. Dicionário Brasileiro de Turismo. Rio de Janeiro: Colorama, 1975.

MOREIRA, A. C. dos S. Terminologia e tradução: criação de uma base de dados terminológica do turismo baseada num corpus paralelo português-inglês. Tese de doutorado. 2010. Universidade de Vigo, Departamento de Tradución e Lingüística, Facultade de Filoloxía e Tradución.

ORGANIZAÇÃO MUNDIAL DO TURISMO. Introdução ao Turismo. São Paulo: Roca, 2001.

REAL ACADEMIA ESPAÑOLA. Diccionario Panhispánico de Dudas. Madrid: Santillana, 2005. Disponível em: <http://www.rae.es/recursos/diccionarios/dpd>. Acesso em: 01 out. 2015.

SWARBROOKE, J.; HORNER, S. Comportamento do consumidor no turismo. São Paulo: Aleph, 2002.

TAGNIN, S. E. O. Os corpora: Instrumentos de auto-ajuda para o tradutor. Cadernos de Tradução, Florianópolis, 2002, v.09, p.191-213.

TUBINO, M. J. G.; TUBINO, Fábio Mazeron; GARRIDO, F. A. C.. Dicionário enciclopédico Tubino do esporte. Rio de Janeiro: Senac, 2007.

WIDMER, G. M.; MELO, A. J. de S.; KÖRÖSSY, N.; CORDEIRO, I. As Normas Técnicas da ABNT sobre Turismo de Aventura. VII Seminário da Associação Nacional Pesquisa e Pós-Graduação em Turismo, 20 e 21 de setembro de 2010 - Universidade Anhembi Morumbi - UAM/ São Paulo/SP. 